\title{
LARK BUNTING - WESTERN PRAIRIE MARVEL
}

ROBERT W. NERO, Box 14, 1495 St. James Street, Winnipeg, Manitoba. R3H OW9

After seeing more than 50 raptors of 6 different species in one afternoon, I was unprepared for the excitement I still felt upon seeing a field of Lark Buntings. We had been driving through "Poverty Plains," an area of extreme southwestern Manitoba where there are a few large tracts of native mixed-grass prairie. The open grassland, mostly unimproved pasture, attracts Ferruginous Hawks, Burrowing Owls, Loggerhead Shrikes and Baird's Sparrows, all threatened or endangered species. We also found Lark Sparrows, Grasshopper Sparrows, Chestnutcollared Longspurs, Sprague's Pipits and Upland Sandpipers. But it was the Lark Buntings that excited me most. These small, blunt-headed finches, especially the conspicuous males with their striking white wingpatches, made me laugh with joy. Though I hadn't seen breeding Lark Buntings for nearly 24 years, I had once studied them closely. The sight

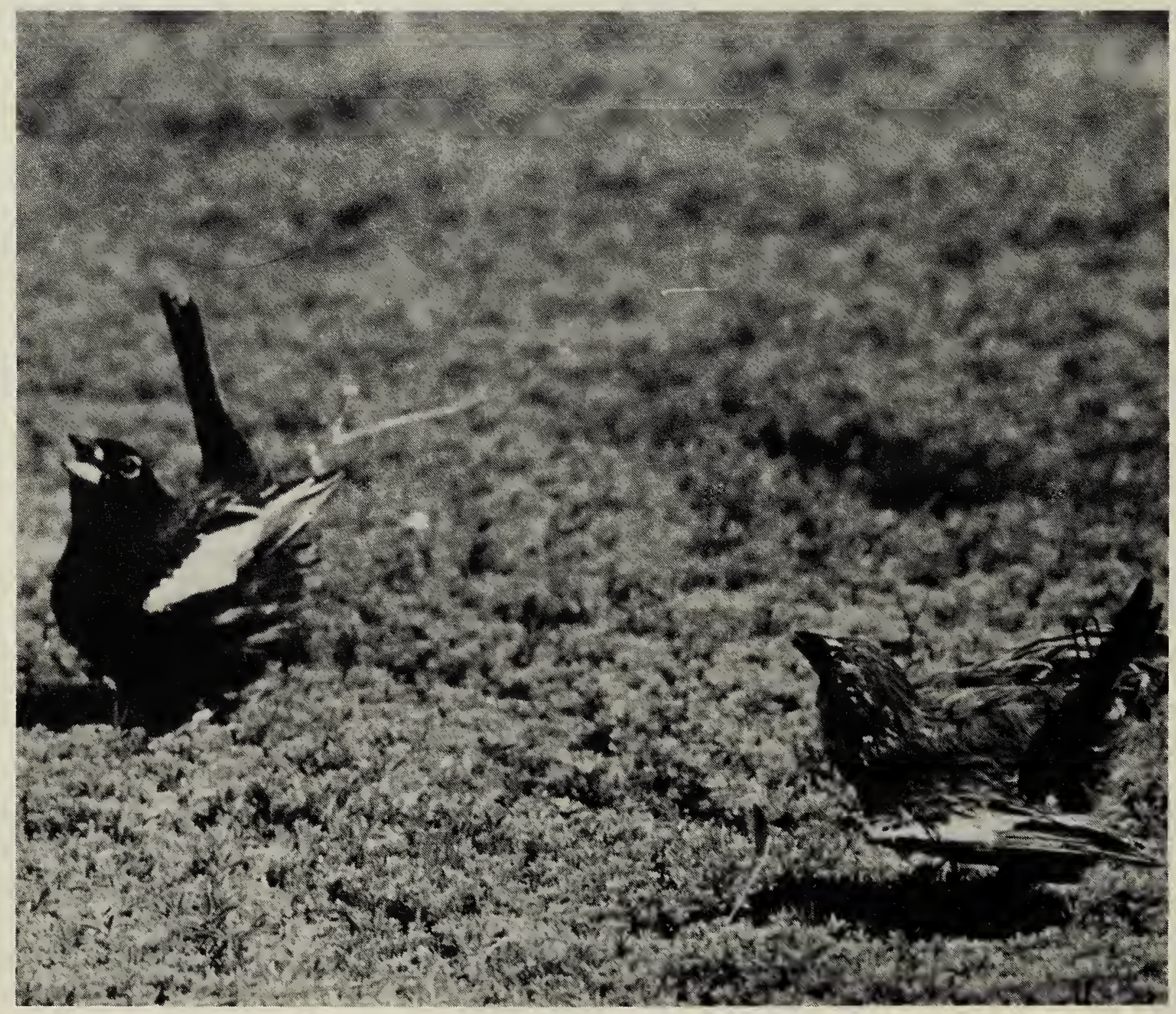

Male Lark Bunting in extreme post-copulatory posture. Mounted fema'e on right. (White eye-ring is an anomaly.)

Robert W. Nero 


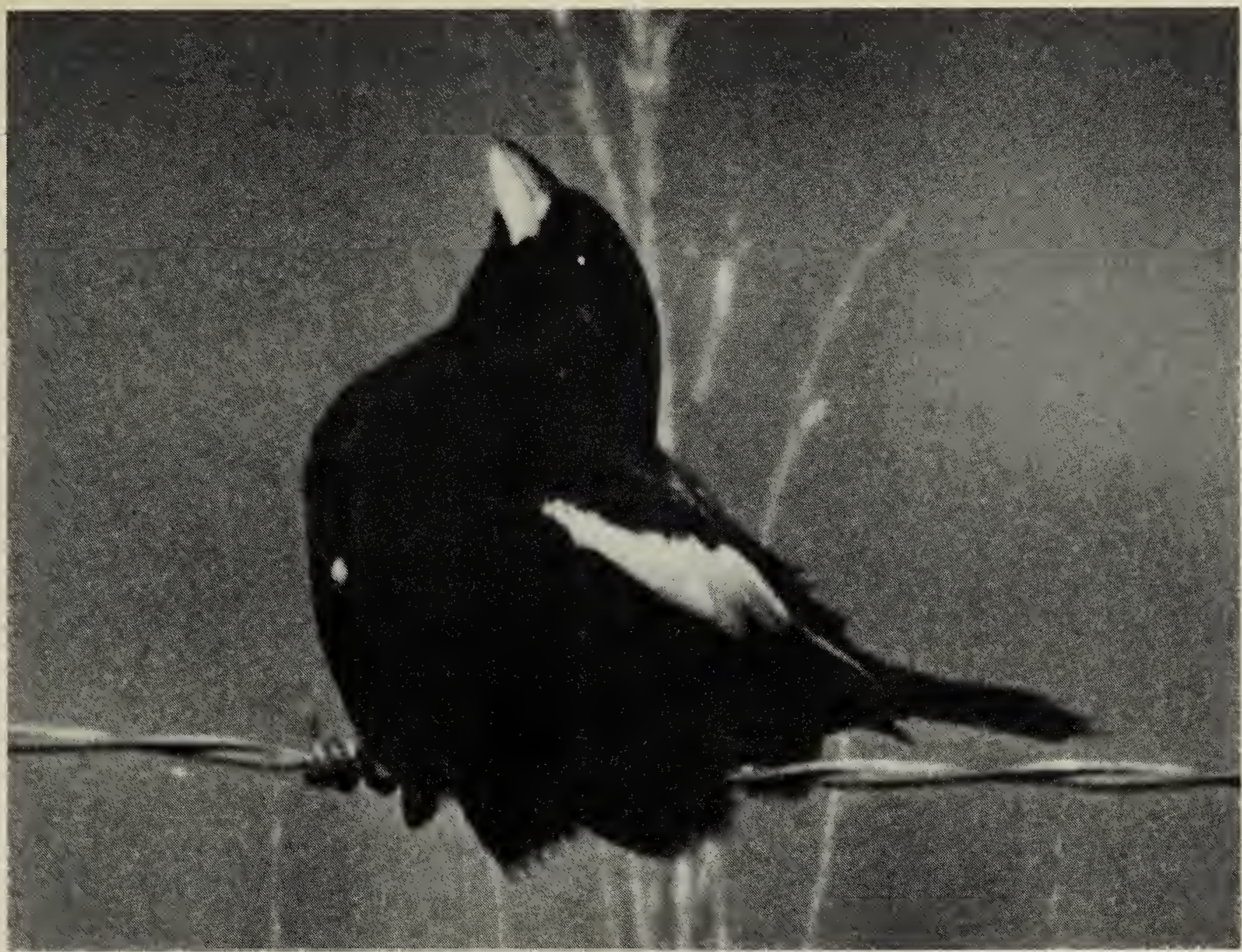

Male Lark Bunting in post-copulatory display on fence wire.

Robert W. Nero

of several males in wild pursuit of a darting female reminded me of my earlier affair with this bird of the western prairies.

In 1964 Lark Buntings irrupted over a large area of the Northern Great Plains and east into southwestern Minnesota. That year they were numerous in southern Saskatchewan; many appeared overnight on remnant native prairie stands near where I lived in Regina. Captivated by this newcomer to my backyard, I undertook some simple experiments to try to elicit mating behaviour, the main results of which were eventually described in a note in the Wilson Bulletin in $1982 .^{2}$

By using a mounted male and female Lark Bunting it was possible for me to observe and photograph some previously unreported Lark Bunting behaviour. A female dummy or mounted bird arranged in solicitation pose is a strong sexual stimulus. Even a poorly mounted bird will attract males. It may seem strange that birds should respond to such a model, but this three-dimensional image is a powerful stimulus. After all, despite our intelligence, we humans respond in not unsimilar fashion to mere two-dimensional images in pictures and film.

In my first experiment I placed a male and female dummy about 15 feet from a nest with four eggs. Both members of the pair and several other males responded to the dummies and this led to interactions between the male and his mate and the other males. I was especially intrigued by responses of males. A male's approach to the female dummy began with a run, head lowered, breast feathers spread, crown raised, followed by an upright pos- 


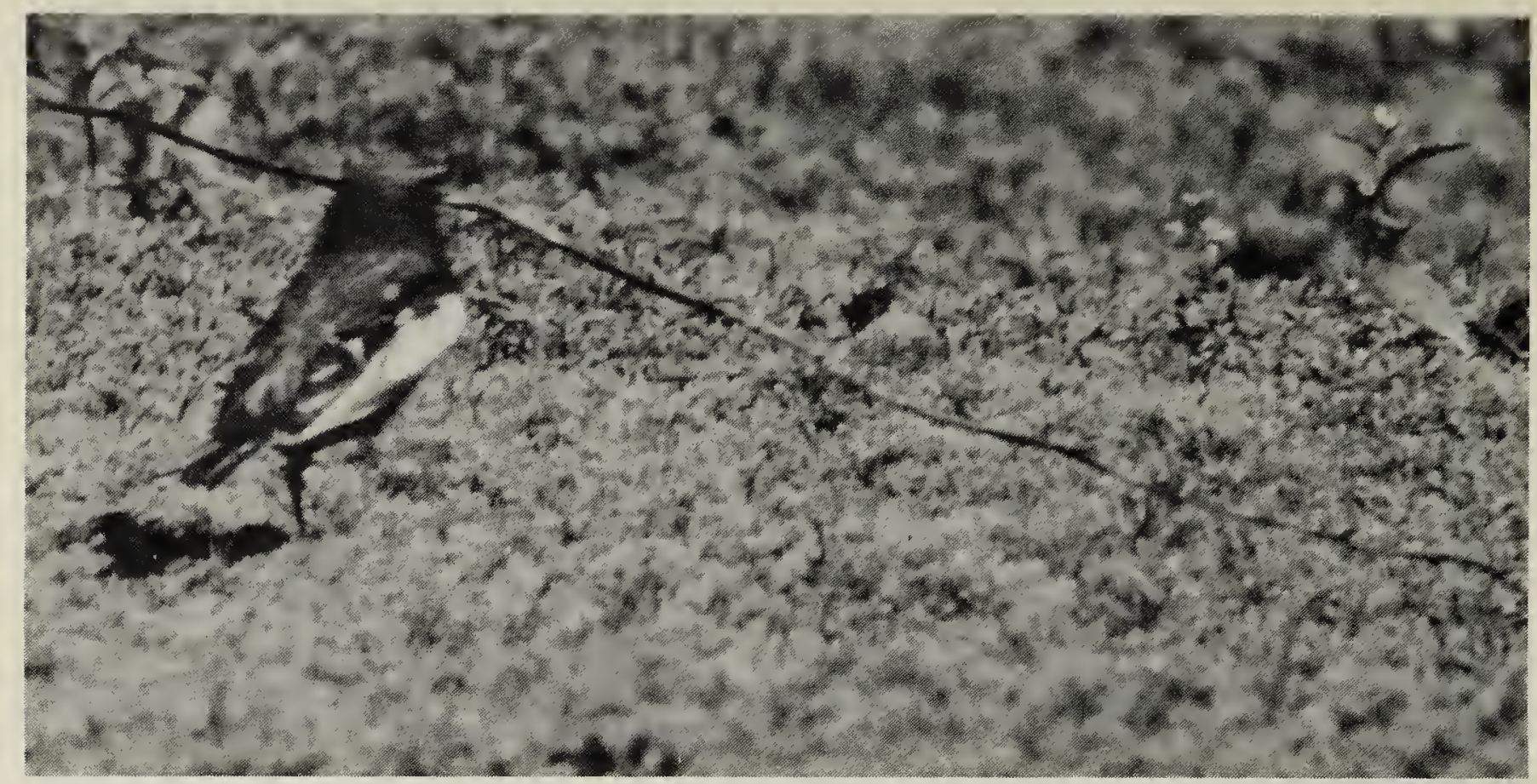

Male Lark Bunting carrying a 20 -inch long weedstalk toward mounted female.

Robert W. Nero

ture as he came up behind the dummy and hopped onto its back. When he copulated, the head and neck feathers were compressed. It is what the male Lark Bunting does afterwards that is so engrossing. Instead of flying away after dismounting, the male jumps off, runs off a few feet, then turns and goes into a post-copulatory display, a static posture held rigidly for up to two minutes. For the ever-active male to suddenly stop moving and hold itself in a strained position, as if in a trance, is a surprising performance. We don't often see birds sitting so still and in this instance the effect is dramatic. One moment the male is soaring overhead in rollicking song, the next, it is frozen at our feet, drawn by the stimulus of the unrelenting female dummy. It is almost unbearable, ecstasy prolonged. I learned that this curious behaviour could be elicited by placing the female dummy wherever there were Lark Buntings.

In extreme post-copulatory display, and this usually occurred after an intense bout of copulation, the tail is held straight up, the head is with- drawn with bill lifted and open, and often the nictitating membrane is blinked. The wings are held partly open, usually the one on the side toward the dummy being held out more. In many respects, the male's post-copulatory posture resembles female sexual display, that is, readiness for copulation. Both male and female displays seem to be derived from a basic passerine juvenile foodbegging posture. At first the postcopulatory display is rigidly held, but then the male gradually relaxes, the tail begins to lower, the wings quiver a bit, and the male comes back to life. Then the whole sequence may begin all over again, the male "winding up" and running back to the dummy for yet another episode. (Though my experiments have never caused a male Red-winged Blackbird to perform post-copulatory display, they have induced it in the Yellow-headed Blackbird, Chestnutcollared Longspur and McCown's Longspur.)

A female dummy in a position of sexual invitation seems irresistible to a breeding male. The excited male rushes to the dummy and frenziedly 
copulates, at times even depositing semen. The mesmerized male returns again and again to this love-object, sometimes grasping at straws, as it were, literally picking up a billful of grass stems as if for an offering. Once a male ran toward the dummy while holding a weedstalk about 20 inches long, a comical sight. I judged this to be part of courtship display, for males in many species of birds demonstrate with nesting material. In this connection, the conspicuous aerial display of the male, which is often followed by his suddenly dropping down into vegetation, appears to be part of a sequence of movements leading the female to nesting behaviour. The business of the male frantically picking up nest material is probably part of the pattern, but this requires further study.

Seeing Lark Buntings again out on the open, almost barren plains of southwestern Manitoba made me think that there may be much to be learned from this species. This bird's tendency to fluctuate in abundance from year to year has been noted by several writers. Wilson Tout, a $\mathrm{Ne}$ braska birder, commented in 1902 that it appeared to be more abundant in dry than in wet years. ${ }^{1}$ Its appearance in large numbers in southwestern Manitoba in 1988 certainly coincided with widespread drought conditions. But other observers have associated its appearance with good crop years. Whenever it appears as a breeding species it attracts a lot of attention, its flight song, in particular, causing people to marvel at this nomad's attractiveness. In A. C. Bent's "Life Histories," always a good source of original material, there are some colourful descriptions of Lark Buntings. ${ }^{1}$ Montana birder Charles $L$. Whittle wrote: "In every direction, first here and then there, often in a dozen places at once, Lark Buntings shot into the air, usually from the ground, as though propelled from guns, pouring out the most infectious and passionate song, perhaps, sung by any bird in the United States." Roy M. Langdon had this to say: "Several times I have heard him in the sunlit, sparkling rain. He is vocal when other birds seek shelter. Being strong of wing, he flies up to greet with song the cooling breezes or the gale that brings the storm. Sometimes he flies almost vertically up the wind, turns, and sails rapidly down the wind, bubbling with glee."

The Lark Bunting's preferred habitat on the western prairies is said to be the "sage prairie." Though it will use native prairie, it also seeks out disturbed sites where wolf-willow or silverberry (Elaeagnus commutata) and snowberry (Symphoricarpos sp.) are abundant. Its disappearance from the eastern parts of its range following the demise of the prairies, suggests that the Lark Bunting may be more vulnerable than we know. In our efforts to rescue endangered species we may be overlooking significant ecological relationships. Who knows what clues the Lark Bunting may provide? Spirited, sociable, conspicuous, with musical song that is as much a part of the landscape as native shrubs and grasses, the Lark Bunting is an exciting member of the High Plains avifauna of western North America.

1. BENT, A.C. 1968. Life histories of North American cardinals, grosbeaks, buntings, towhees, finches, sparrows, and allies. Part 2. Dover, Toronto. Pp. 603-1249.

2. NERO, R.W. 1982. Post-copulatory display in Lark Bunting and other species. Wils. Bull. 94:585-590. 